\title{
Development and characterization of a High-Temperature Proton-Transfer-Reaction Mass Spectrometer (HT-PTR-MS)
}

\author{
T. Mikoviny, L. Kaser, and A. Wisthaler \\ Institut für Ionenphysik und Angewandte Physik, Universität Innsbruck, Innsbruck, Austria \\ Received: 3 December 2009 - Published in Atmos. Meas. Tech. Discuss.: 15 January 2010 \\ Revised: 12 April 2010 - Accepted: 23 April 2010 - Published: 3 May 2010
}

\begin{abstract}
We have developed a High-Temperature ProtonTransfer-Reaction Mass Spectrometer (HT-PTR-MS) in which both the ion source and the ion drift tube can be continuously operated at temperatures up to $250{ }^{\circ} \mathrm{C}$. The instrument was characterized in a high $E / N$-mode $(130 \mathrm{Td})$ and in a low $E / N$-mode $(87 \mathrm{Td})$ at an operating temperature of $200^{\circ} \mathrm{C}$. Instrumental sensitivities and $2 \sigma$-detection limits were on the order of $50-110 \mathrm{cps} / \mathrm{ppb}$ and $100 \mathrm{ppt}(1 \mathrm{~s}$ signal integration time), respectively. The HT-PTR-MS is primarily intended for measuring "sticky" or semi-volatile trace gases. Alternatively, it may be coupled to a particle collection/thermal desorption apparatus to measure particle-bound organics in near real-time. In view of these applications, we have measured instrumental response times for a series of reference compounds. $1 / \mathrm{e}^{2}$-response times for dimethyl sulfoxide, ammonia and monoethanolamine were in the sub-second to second regime. $1 / \mathrm{e}^{2}$-response times for levoglucosan, oxalic acid and cis-pinonic acid ranged from 8 to $370 \mathrm{~s}$.
\end{abstract}

\section{Introduction}

Proton-Transfer-Reaction Mass Spectrometry (PTR-MS) is a highly sensitive, real-time analytical technique for detecting volatile organic compounds (VOCs) in air, which was developed in the mid-nineties in the laboratories of the Institute of Ion Physics at the University of Innsbruck (Hansel et al., 1995). PTR-MS combines the concepts of soft, non-fragmenting chemical ionization of organics via proton transfer reactions from $\mathrm{H}_{3} \mathrm{O}^{+}$ions (Hunt and Ryan, 1972) and of quantitative product ion formation in an ion drift tube (McFarland et al., 1973). $\mathrm{H}_{3} \mathrm{O}^{+}$ions are produced in a glow discharge ion source and injected into an

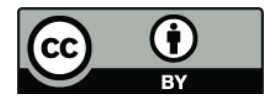

Correspondence to: A. Wisthaler (armin.wisthaler@uibk.ac.at) ion drift tube which is continuously flushed with analyte air. Organic molecules become protonated in collisions with $\mathrm{H}_{3} \mathrm{O}^{+}$ions and are subsequently subjected to mass spectrometric analysis. Most Innsbruck-type PTR-MS instruments use quadrupole mass spectrometers for analysis, but recently more sophisticated mass spectrometric instrumentation (including cylindrical/linear ion traps, time-of-flight mass spectrometers) has become available (Prazeller et al., 2003; Warneke et al., 2005; Mielke et al., 2008; Jordan et al., 2009a). In the field of atmospheric chemistry, PTR-MS is nowadays a well-established technique that is routinely used for on-line detection of small VOCs such as methanol, acetone, isoprene, benzene and toluene (see recent review by de Gouw and Warneke, 2007). It is implicitly known in the PTR-MS user community that PTR-MS instruments perform poorly for compounds that readily adsorb or condense onto surfaces. The combination of a low sampling flow through the drift tube $(15-20 \mathrm{ml} / \mathrm{min})$, stainless steel surfaces in the inlet and in the drift tube, and a relatively low maximum continuous operating temperature $\left(120^{\circ} \mathrm{C}\right)$ promote surface losses and memory effects. The maximum operating temperature is limited by the thermal stability of vacuum gaskets and insulating spacers used in the ion source and in the drift tube. Older generation instruments used Viton gaskets, while newer generation instruments (from now on referred to as standard instruments) use Teflon PTFE gaskets (Steinbacher et al., 2004). At continuous operating temperatures above $120^{\circ} \mathrm{C}$, Teflon PTFE slowly deforms which leads to leaking and ultimately to instrument failure. Furthermore, fluoropolymers and fluorocarbon elastomers show increased outgassing at elevated temperature which increases the instrumental background and deteriorates the limit of detection. Here, we report on the development and characterization of a High-Temperature Proton-Transfer-Reaction Mass Spectrometer (HT-PTR-MS) that can continuously be operated at temperatures up to $250^{\circ} \mathrm{C}$. The HT-PTR-MS is primarily intended for measuring "sticky" or semi-volatile trace gases.

Published by Copernicus Publications on behalf of the European Geosciences Union. 


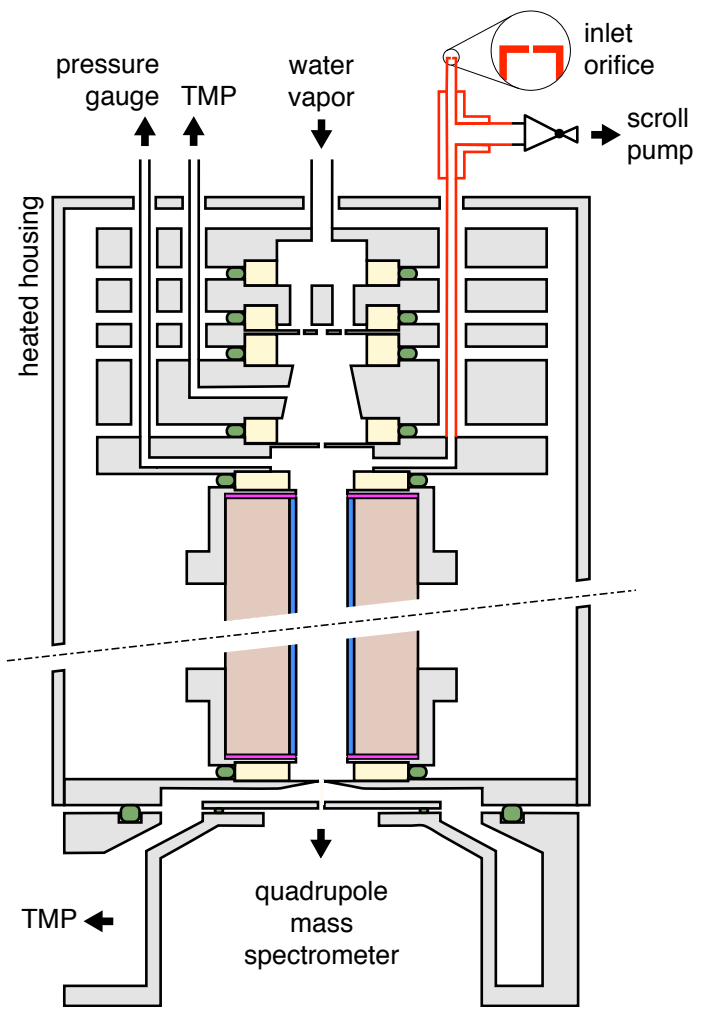

Fig. 1. Scheme of the ion source and the resistive glass drift tube in the HT-PTR-MS. Material color-coding: stainless steel (grey), PEEK (yellow), Kalrez ${ }^{\circledR}$ (green), flexible graphite (magenta), resistive glass (blue), MACOR ${ }^{\circledR}$ (light brown), passivated stainless steel (red). TMP: turbomolecular pump.

In the future, it will be combined with a particle collection/thermal desorption apparatus to measure particle-bound organics in near real-time (e.g. Holzinger et al., 2010; Hohaus et al., 2010). In view of these applications, we have performed instrumental response time tests with a series of reference compounds (dimethyl sulfoxide, monoethanolamine, ammonia, levoglucosan, oxalic acid and cis-pinonic acid). Most of this species are of atmospheric relevance and the development of on-line chemical ionization detection methods for these compounds is highly desirable.

\section{Experimental}

\subsection{The High-Temperature Proton-Transfer-Reaction Mass Spectrometer (HT-PTR-MS)}

The HT-PTR-MS is schematically shown in Fig. 1. It has a similar set-up as the standard PTR-MS instrument. The most important modification was the use of a resistive glass drift tube (Photonis Inc., Sturbridge, MA, USA) instead of a segmented drift tube consisting of stainless steel rings with Teflon PTFE insulating spacers. The use of a resistive glass
Table 1. Materials used in the HT-PTR-MS and their maximum continuous operation temperatures $\left(t_{\max }\right)$.

\begin{tabular}{lll}
\hline Material & Use & $t_{\max } /{ }^{\circ} \mathrm{C}$ \\
\hline Kalrez $^{\circledR}$ Spectrum $^{\mathrm{TM}} 6375$ & sealing & 275 \\
VICTREX $^{\circledR}$ PEEK $^{\mathrm{TM}} 450 \mathrm{G}$ & sealing & 260 \\
MACOR $^{\circledR}$ & drift tube holder & 800 \\
Flexible graphite & electrically & 450 \\
& conductive sealing & \\
Resistive glass & of the drift tube & \multirow{2}{*}{400} \\
\hline
\end{tabular}

drift tube ensures a high homogenity in the electric drift field. Thornberry et al. (2009) have previously used a resistive glass drift tube in their PTR-MS type instrument. We used a glass drift tube of $150 \mathrm{~mm}$ length (ID: $8.3 \mathrm{~mm}$; OD: $10.9 \mathrm{~mm}$ ) with an end-to-end resistivity of $20 \mathrm{G} \Omega$. The resistive glass drift tube was coupled to the electro-optic entrance lens and exit lens using an electrically conductive flexible graphite foil (SIGRAFLEX ${ }^{\circledR}$, SGL Group, Wiesbaden, Germany). A MACOR ${ }^{\circledR}$ hollow cylinder was used to keep the drift tube in place. Resistive glass can, in principle, be operated up to a maximum temperature of $400{ }^{\circ} \mathrm{C}$. Sealing materials have, however, lower maximum operating temperatures (see Table 1) and we can currently not heat the drift tube to temperatures higher than $250^{\circ} \mathrm{C}$. For the studies reported herein, we used a continuous operation temperature of $200^{\circ} \mathrm{C}$. The drift tube temperature was measured directly at the surface of the resistive glass tube. The pumping configuration was the same as in the standard instrument: the drift tube was pumped by a TMH 071P turbomolecular pump (Pfeiffer Vacuum, Asslar, Germany), the detection region was differentially pumped by an TMH 071P turbomolecular pump (Pfeiffer Vacuum, Asslar, Germany) and by a Varian Turbo-V 300HT MacroTorr turbomolecular pump (Varian Vacuum Technologies, Torino, Italy). A QMA 400 (Pfeiffer Vacuum, Asslar, Germany) quadrupole mass spectrometer was used for mass spectrometric analysis. The range of the drift tube operation parameters was the same as in the standard instrument: $2.0-2.4 \mathrm{mbar}$ drift tube pressure, $80-140 \mathrm{Td}$ reduced electric field $E / N$ (with $E$ being the electric field across the drift tube and $N$ being the gas number density; $1 \mathrm{Td}=10^{-17} \mathrm{~cm}^{2} \mathrm{~V}$ molecule ${ }^{-1}$ ). We typically used two operating conditions: $130 \mathrm{Td}(600 \mathrm{~V}$, $2.00 \mathrm{mbar}, 200^{\circ} \mathrm{C}$; from now on referred to as the high $E / \mathrm{N}$ mode) or $87 \mathrm{Td}\left(400 \mathrm{~V}, 2.00 \mathrm{mbar}, 200^{\circ} \mathrm{C}\right.$; from now on referred to as low $E / N$-mode). In the standard instrument, the segmented drift tube is slightly bent. The glow discharge ion source produces energetic photons and the bending prevents them from reaching the detection region. Since we used a straight glass drift tube, the design of the ion source had to be changed to avoid photon noise. The single on-axis hollow cylinder cathode used in the standard instrument was replaced by three off-axis hollow cylinder cathodes each with 
an inner diameter of $4 \mathrm{~mm}$. The exit anode lens had one central orifice of $0.8 \mathrm{~mm}$ diameter and three $0.5 \mathrm{~mm}$ diameter orifices which were aligned with the cathode hollow cylinders. The three off-axis orifices had the primary function of reducing the pressure in the discharge region, thus improving the discharge stability. A water vapor flow of $8 \mathrm{ml} / \mathrm{min}$ was supplied to the ion source via a low- $\Delta \mathrm{p}$ flow controller (Bronkhorst High-Tech BV, Ruurlo, NL). The ion source was manufactured from stainless steel, the spacers were made of PolyEtherEtherKetone (PEEK). Kalrez ${ }^{\circledR}$ Spectrum $^{\mathrm{TM}} 6375$ O-rings were placed outside the PEEK rings to provide additional vacuum sealing (see also Fig. 1). The use of PEEK and Kalre ${ }^{\circledR}$ currently limits the maximum operating temperature of the HT-PTR-MS to $250^{\circ} \mathrm{C}$. A detailed overview of all the materials used for the construction of the HT-PTR-MS and their maximum continuous operating temperatures is given in Table 1. The inlet of the HT-PTR-MS was made of a $35 \mu \mathrm{m}$ critical orifice placed on a $30 \mathrm{~mm}$ long passivated stainless steel tube (OD: $3.175 \mathrm{~mm})\left(\right.$ Sulfinert $^{\circledR}$, Restek, Bellefonte, MA, USA). The orifice was pumped at $80 \mathrm{ml} / \mathrm{min}$ by a scroll pump (TriScroll 600, Varian Vacuum Technologies, Torino, Italy). A lower-capacity pump can be used in combination with a smaller critical orifice. A flow of $15 \mathrm{ml} / \mathrm{min}$ was delivered to the drift tube while the overflow of $65 \mathrm{ml} / \mathrm{min}$ was branched off into the scroll pump (see Fig. 1). Both the ion source and the drift tube were enclosed in a stainless steel cylinder (ID: $90 \mathrm{~mm}$ ) surrounded by a heating jacket heated to $250^{\circ} \mathrm{C}$. Superwool ${ }^{\circledR} 607$ (Thermal Ceramics, Morgan Crucible, Windsor, UK) was used as thermal insulation material.

\subsection{Set-up for instrument calibration and background characterization}

The HT-PTR-MS was calibrated using a calibration gas standard (Air Env., Denver, CO, USA) containing $1.00 \mathrm{ppm}$ of acetone, $1.02 \mathrm{ppm}$ of methyl ethyl ketone, $0.70 \mathrm{ppm}$ of hexanal and $0.28 \mathrm{ppm}$ of decanal (accuracy: $\pm 5 \%$ for each of the compounds). We only targeted oxygenated hydrocarbons in our calibration studies. The standard was dynamically diluted to ppb levels using humidified zero air. Zero air (2000-3000 $\mathrm{ml} / \mathrm{min}$ ) was produced by passing dried compressed air from the in-house supply over a $\mathrm{Pt} / \mathrm{Pd}$ catalyst $\left(\mathrm{Pt} / \mathrm{PtO}_{2} / \mathrm{Pd} / \mathrm{PdO}\right.$, EnviCat ${ }^{\circledR}$ VOC5528, Süd-Chemie, Munich, Germany) operated at $380^{\circ} \mathrm{C}$. The air was subsequently humidified using a water bubbler at $20^{\circ} \mathrm{C}$. The humidity was kept at constant levels $\left(\sim 90 \% \mathrm{RH}, 25^{\circ} \mathrm{C}\right)$ throughout the experiments. The instrumental background was measured by delivering humidified zero air to the instrument.

\subsection{Set-up for response time measurements}

The critical orifice inlet was continuously flushed with heated $\left(120-180^{\circ} \mathrm{C}\right)$ humidified zero air $(2000-3000 \mathrm{ml} / \mathrm{min})$. A $\mu \mathrm{l}$-syringe (Hamilton 1705RN, $50 \mu \mathrm{l}$ ) was placed into the stream of zero air at a distance of $2 \mathrm{~mm}$ from the critical orifice to spike the zero air with different test compounds at different concentration levels. A constant liquid sample flow was injected using a syringe pump (Harvard Apparatus Pico Plus, Holliston, MA, USA). Chemicals used were dimethyl sulfoxide ( $\geq 99.9 \%$, Sigma-Aldrich), ammonia ( $25 \%$ in $\mathrm{H}_{2} \mathrm{O}$, Merck), monoethanolamine ( $\geq 99.5 \%$, Sigma-Aldrich), levoglucosan ( $\geq 98 \%$, Sigma Aldrich), oxalic acid ( $\geq 99 \%$, Sigma Aldrich), cis-pinonic acid ( $\geq 98 \%$, Sigma-Aldrich). Pure compounds were diluted in distilled water to achieve approximately $100 \mathrm{ppm}$ mixing ratio in solution. After achieving a steady-state ion signal from the spiked compound, the needle was mechanically removed from the zero air flow and the fall-off of the ion signal was monitored. Ion signal dwell times were compound specific and chosen as follows: dimethyl sulfoxide $(\mathrm{m} / \mathrm{z}, 79$ : $0.1 \mathrm{~s})$, ammonia $(\mathrm{m} / \mathrm{z}, 18: 20 \mathrm{~ms})$, monoethanolamine $(\mathrm{m} / \mathrm{z}$ 62: $0.5 \mathrm{~s})$, levoglucosan $(\mathrm{m} / \mathrm{z}$ 85: $0.5 \mathrm{~s})$, oxalic acid $(\mathrm{m} / \mathrm{z}$ 91: $0.5 \mathrm{~s})$, cis-pinonic acid $(\mathrm{m} / \mathrm{z}$ 167: $1 \mathrm{~s})$

\section{Results and discussion}

\subsection{Ion source performance}

Typical reagent ion count rates in the new HT-PTR-MS were $7 \times 10^{6} \mathrm{cps}$ of $\mathrm{H}_{3} \mathrm{O}^{+}$ions $\left(\mathrm{O}_{2}^{+}: 5 \times 10^{4} \mathrm{cps} ; \mathrm{H}_{3} \mathrm{O}^{+}\left(\mathrm{H}_{2} \mathrm{O}\right)\right.$ : $\left.8 \times 10^{5} \mathrm{cps}\right)$ in the high $E / N$-mode and $4.5 \times 10^{6} \mathrm{cps}$ of $\mathrm{H}_{3} \mathrm{O}^{+}\left(\mathrm{H}_{2} \mathrm{O}\right)$ ions $\left(\mathrm{H}_{3} \mathrm{O}^{+}: 3 \times 10^{5} \mathrm{cps} ; \mathrm{O}_{2}^{+}: 1 \times 10^{4} \mathrm{cps}\right.$; $\left.\mathrm{H}_{3} \mathrm{O}^{+}\left(\mathrm{H}_{2} \mathrm{O}\right)_{2}: 3 \times 10^{5} \mathrm{cps}\right)$ in the low $E / N$-mode. We limited the ion source discharge current to $3.5 \mathrm{~mA}$. A minimum of $50 \%$ increase in the primary ion signal output was obtained at discharge currents $>8 \mathrm{~mA}$. Previous experience has shown that higher discharge currents reduce the lifetime of PTR-MS ion sources. We thus kept the discharge current relatively low to avoid frequent servicing. We used a relatively high water vapor flow $(8 \mathrm{ml} / \mathrm{min})$ to maintain the $\mathrm{O}_{2}^{+}$fraction well below $1 \%$ of the total reagent ion counts. In addition, the quadrupole mass spectrometer was optimized for the detection of high $\mathrm{m} / \mathrm{z}$-signals by increasing the reference potential of the mass spectrometer lenses (V1 in the Pfeiffer IS 420 supply) from $\sim 50 \mathrm{~V}$ to $\sim 70 \mathrm{~V}$. This resulted in a $\sim 25 \%$ higher detection efficiency for ion signals with $m / z>100$, but also in a $\sim 10 \%$ drop of the primary ion signal. If only optimized for primary ion signal output and detection, our new HT-PTR-MS achieved similar primary ion signal intensities as standard PTR-MS instruments $\left(>10^{7} \mathrm{cps}\right)$.

\subsection{Sensitivity}

We calibrated the instrument with a series of oxygenated VOCs including acetone, methyl ethyl ketone, hexanal and decanal. The sensitivity of the PTR-MS for a specific compound primarily depends on the dipole moment and on the 

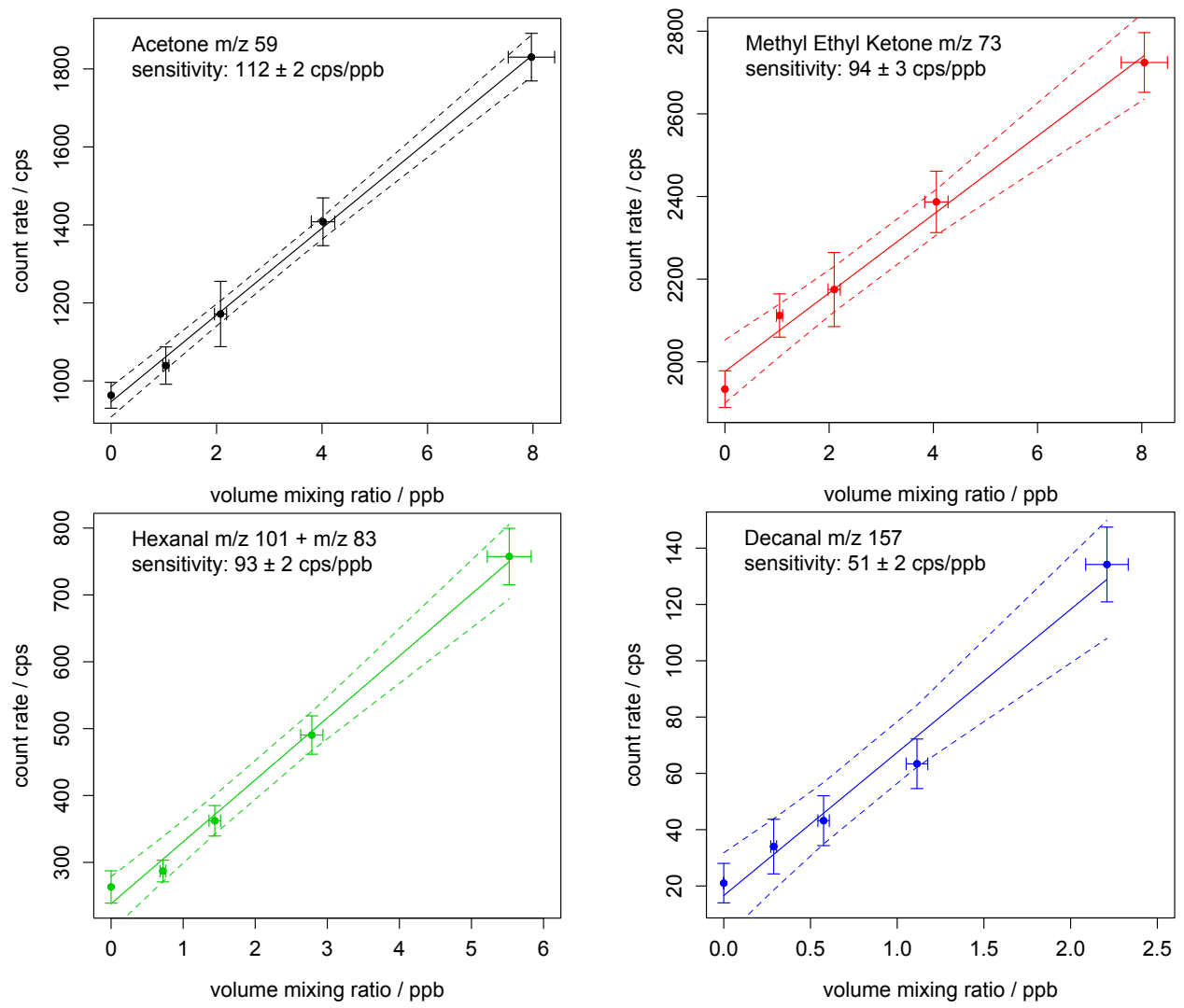

Fig. 2. Calibration curves for acetone, methyl ethyl ketone, hexanal and decanal measured at $87 \mathrm{Td}$ and $200{ }^{\circ} \mathrm{C}$ drift tube temperature. The error bars on the $\mathrm{x}$-axis represent the combined uncertainty from the accuracy of the gas standard and the error associated with the dilution of the standard. The error bars on the y-axis represent the standard deviation of the observed count rates. The dashed lines indicate the $95 \%$ confidence interval of the fitted line.

molecular weight of the analyte molecules. The studied carbonyls may thus serve as proxies for multifunctional compounds of lower volatility with similar dipole moments and molecular weights. Figure 2 shows calibration curves obtained in the low $E / N$-mode. For acetone $(m / 259)$ we observed a sensitivity of $112 \mathrm{cps} / \mathrm{ppb}$. A similar sensitivity was observed in the high $E / N$-mode when the primary ion signal was significantly higher (see Sect. 3.1). We have refrained from normalizing the sensitivity as it is frequently done in the PTR-MS user community. Normalized sensitivity is not a useful parameter to characterize and compare PTR-MS instruments because it does not reflect differences in primary ion signal intensities. It is again pointed out that the instrument was not tuned for maximum sensitivity (see Sect. 3.1). Under optimized conditions we achieved acetone sensitivities up to $200 \mathrm{cps} / \mathrm{ppb}$, which is comparable to the performance of standard instruments we deploy in our laboratory. High-end commercial PTR-MS instruments can reach carbonyl sensitivities up to $600 \mathrm{cps} / \mathrm{ppb}$ (Jordan et al., 2009b) at the expense of a relatively high $\mathrm{O}_{2}^{+}$level ( $>1 \%$ of the total reagent ion counts). Sensitivities close to $100 \mathrm{cps} / \mathrm{ppb}$ were observed for methyl ethyl ketone $(\mathrm{m} / \mathrm{z} 73)$ and hexanal $(\mathrm{m} / \mathrm{z}, 101$ and dehydration fragment at $\mathrm{m} / \mathrm{z} 83)$. A factor of 2 drop in sensitivity was measured for decanal $(\mathrm{m} / \mathrm{z} 157)$. The $m / z 139$ fragment was negligibly small in the low $E / N$ mode. Decanal has a similar dipole moment as the other investigated carbonyls which should, in theory, lead to a similar instrumental sensitivity. It is, however, well-known in the PTR-MS community that the QMA 400 mass analyzer strongly discriminates ion signals with $m / z>110$ (e.g. Kim et al., 2009). At $m / z 200$ the detection efficiency is typically only $5-10 \%$ of the detection efficiency obtained at $m / z, 100$. When operated in the high $E / N$-mode, no protonated ions were observed for either hexanal or decanal. This is not the case for standard instruments when operated at comparable $E / N$-levels. Our findings suggest that high-temperature operation $\left(200^{\circ} \mathrm{C}\right.$ vs. $\left.25^{\circ} \mathrm{C}\right)$ promotes fragmentation of protonated hexanal and decanal. A similar effect has been observed in standard instruments for protonated isoprene when the drift tube temperature was raised from $25^{\circ} \mathrm{C}$ to $50^{\circ} \mathrm{C}$. To avoid extensive fragmentation, we recommend operating the HT-PTR-MS in the low $E / N$-mode. For oxygenated 


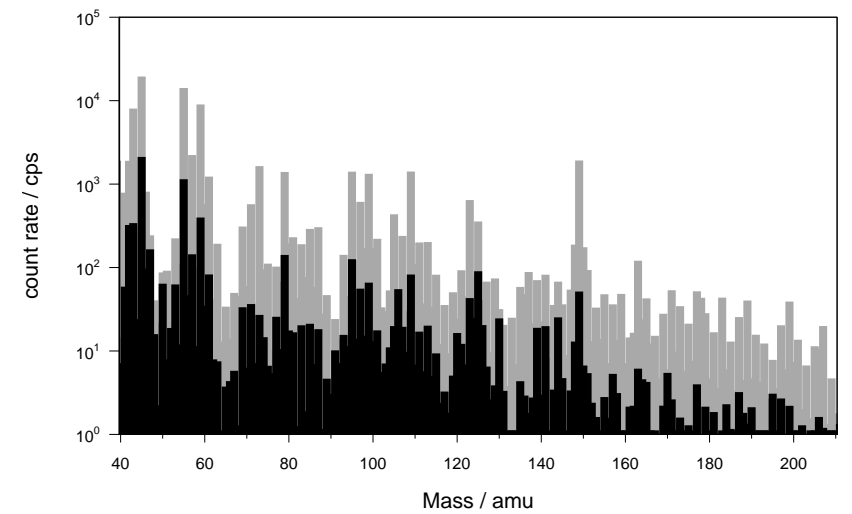

Fig. 3. Instrumental background mass spectrum of the HT-PTRMS recorded after start-up (grey) and after one-week of continuous operation (black); both mass spectra were recorded at an HT-PTRMS operational temperature of $200^{\circ} \mathrm{C}$.

species (e.g. analytes containing hydroxyl, carbonyl or carboxyl groups) we do not expect any humidity dependence in sensitivities even if the instrument is operated in the low $E / N$-mode. Oxygenates react at similar rates with both $\mathrm{H}_{3} \mathrm{O}^{+}$ and $\mathrm{H}_{3} \mathrm{O}^{+}\left(\mathrm{H}_{2} \mathrm{O}\right)$ ions. Thus, even if relative abundances of $\mathrm{H}_{3} \mathrm{O}^{+}$and $\mathrm{H}_{3} \mathrm{O}^{+}\left(\mathrm{H}_{2} \mathrm{O}\right)$ ions vary with humidity, product ion count rates remain identical or very similar. We spiked $\sim 10 \mathrm{ppb}$ of our carbonyl mix into completely dry and humid air $\left(\sim 90 \% \mathrm{RH}, 25^{\circ} \mathrm{C}\right)$, respectively. For both conditions we observed identical signal responses to within $\pm 5 \%$.

\subsection{Instrumental background and detection limit}

The operation of PTR-MS instruments at elevated temperatures is known to increase the instrumental background due to material outgassing and desorption of surface impurities. Figure 3 shows the instrumental background of the HT-PTRMS recorded after start-up (grey) and after one-week of continuous operation (black) when background levels were at quasi steady-state. Even at steady-state the instrument had elevated background levels $\left(>10^{2} \mathrm{cps}\right)$ for many low $\mathrm{m} / z$ signals $(m / z<80)$. In the mass spectral region above $m / z 100$, background levels were typically below $10 \mathrm{cps}$ (with only few major exceptions, e.g. $\mathrm{m} / \mathrm{z} 106,109,123,125,149$ ). A $7 \mathrm{cps}$ background converts into a $2 \sigma$-detection limit of $100 \mathrm{ppt}$ (signal integration time: $1 \mathrm{~s}$, high $\mathrm{m} / \mathrm{z}$ sensitivity: $\sim 50 \mathrm{cps} / \mathrm{ppb}$ ). We consider material outgassing to be the main source of the observed background. Preliminary results from our laboratory indicate that PEEK shows enhanced outgassing at temperatures above $100^{\circ} \mathrm{C}$.

\subsection{Response time}

We define the response time as the time required to observe a $1 / \mathrm{e}^{2}$-signal decay after instant removal of the analyte from the sampling air $\left(1 / \mathrm{e}^{2}\right.$-response time). For compounds that do not adsorb or condense onto surfaces, the PTR-MS response time is determined by the time required to exchange the sampling air in the inlet and in the drift tube. Wisthaler et al. (2006) reported a response time of $\sim 0.15 \mathrm{~s}$ for pure hydrocarbons (benzene, toluene) using the commercial standard PTR-MS instrument equipped with a low-volume $(1.59 \mathrm{~mm}$ OD) Silcosteel ${ }^{\circledR}$ (Restek, Bellefonte, MA, USA) inlet line kept at $40^{\circ} \mathrm{C}$. A minor tailing effect was observed for small oxy-hydrocarbons such as methanol or acetone (unpublished data). For the HT-PTR-MS we measured an upper limit in the response time of $\sim 0.10 \mathrm{~s}$ for methanol and acetone with no observable tailing. The HT-PTR-MS instrument is primarily intended for measuring "sticky" or semi-volatile trace gases. It is planned to combine it with a particle collection/thermal desorption apparatus to measure particle-bound organics in near real-time. In view of these applications, a set of reference compounds was chosen to perform instrumental response time tests. Most of the tested compounds are of atmospheric relevance and have been previously studied using the standard instrument (Norman et al., 2007; and unpublished data from our laboratory). We can thus refer to these results for comparison. Memory effects are known to be concentration-dependent and our response time tests spanned at least one order of magnitude in analyte concentrations. Initial signal count rates (reported in the figure legends) can be converted into approximate $( \pm 50 \%)$ volume mixing ratios using a sensitivity value of $50 \mathrm{cps} / \mathrm{ppb}$. A more accurate quantification would require detailed studies on ion fragmentation patterns and mass discrimination effects. Signals were normalized to the steady-state starting signal to better compare the results obtained at different analyte levels. Response times were only measured in a humid air matrix. The results of the instrumental response time tests are summarized in Fig. 4. As a general feature we found that response times tend to increase with decreasing analyte concentration. Dimethyl sulfoxide (DMSO), a gas-phase oxidation product of dimethyl sulfide (DMS) involved in marine aerosol formation, contains the sulfinyl group which readily binds to active surface sites. Standard PTR-MS instruments have DMSO response times on the order of minutes (unpublished results from our laboratory). Figure 4a shows that the HT-PTR-MS time response for DMSO was $0.4 \mathrm{~s}$. Ammonia $\left(\mathrm{NH}_{3}\right)$ plays an important role in the atmospheric nitrogen cycle and in particle formation. Norman et al. (2007) reported a $1 / \mathrm{e}^{2}$ time response in the 15 -to- $30 \mathrm{~s}$ regime using a standard instrument that had been optimized for $\mathrm{NH}_{3}$ measurements. We observed $\mathrm{NH}_{3}$ response times in the range of 0.2 to $0.3 \mathrm{~s}$ (Fig. 4b). Monoethanolamine (MEA) was chosen as a gaseous reference compound with two functional groups ( $-\mathrm{OH}$ and $\left.-\mathrm{NH}_{2}\right)$. MEA response times in the standard instrument are on the order of several minutes (unpublished data from our laboratory). Response times on the order of 5-18 s were obtained with the new HT-PTR-MS instrument (Fig. 4c). Levoglucosan is a particle-bound marker for biomass burning with a vapor pressure of $7 \times 10^{-5} \mathrm{mbar}$ 
a)

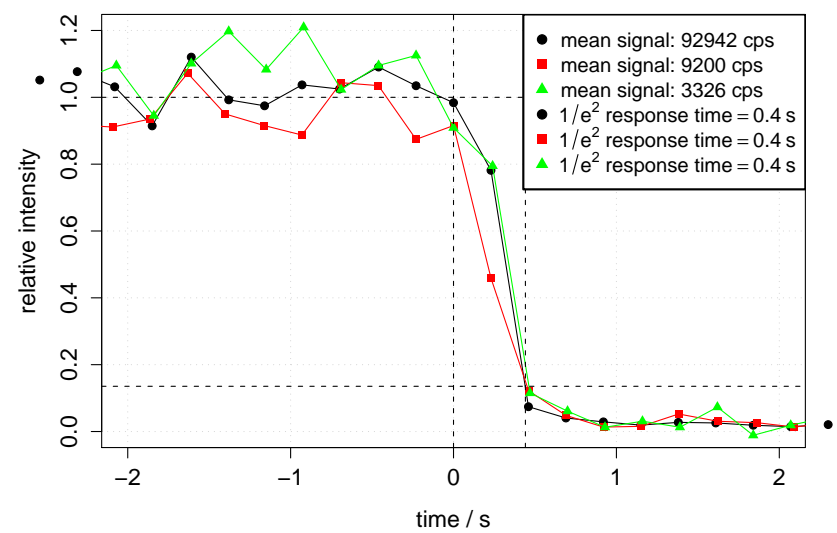

c)

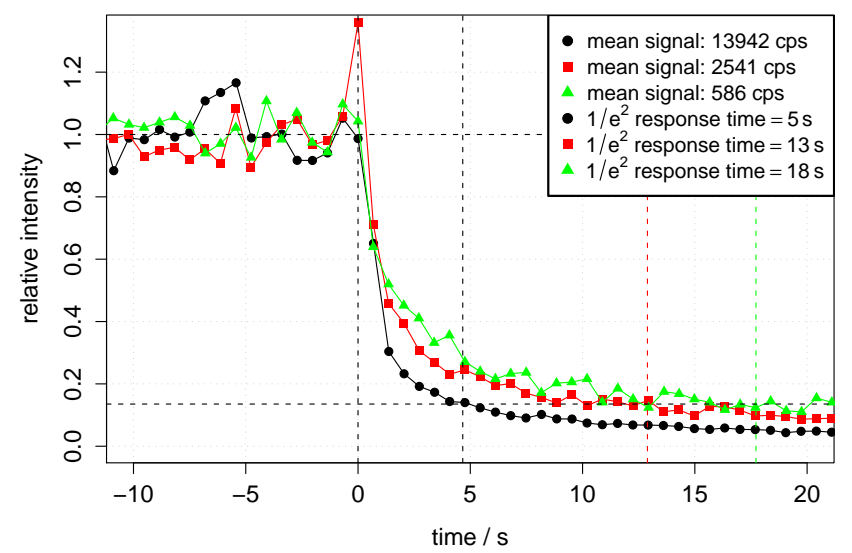

e)

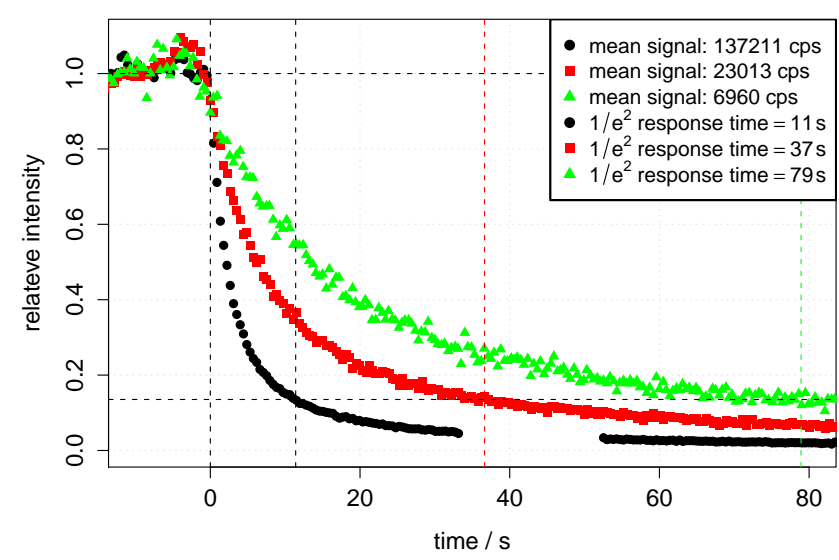

b)

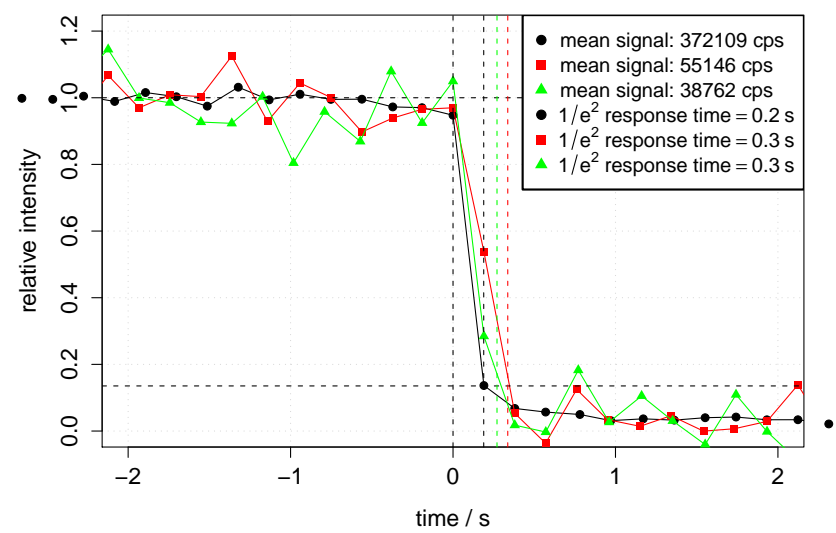

d)

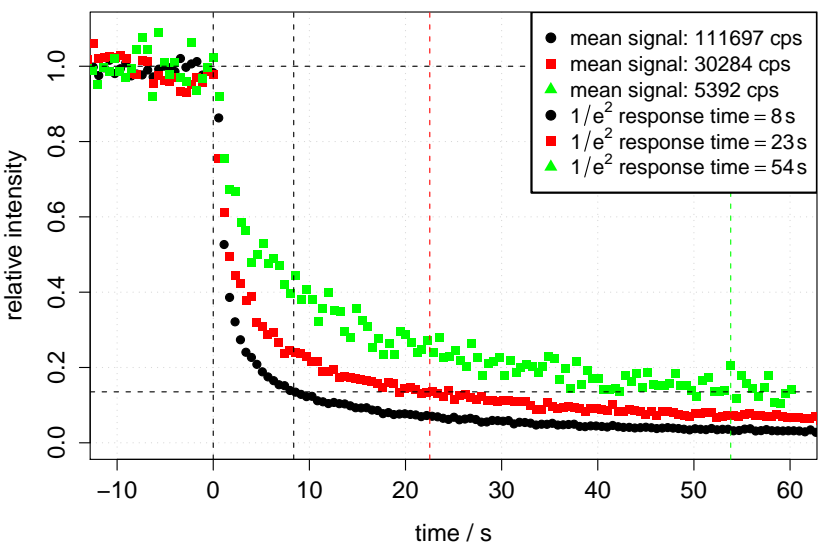

f)

Cis-Pinonic Acid

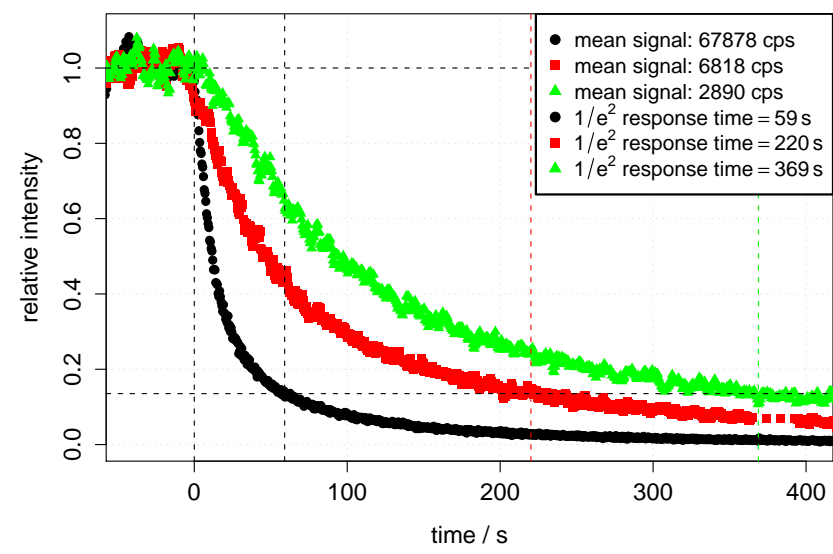

Fig. 4. HT-PTR-MS response times for dimethyl sulfoxide $(\mathrm{m} / \mathrm{z} 79)$, ammonia $(\mathrm{m} / \mathrm{z}, 18)$, monoethanolamine $(\mathrm{m} / \mathrm{z}$, 62), levoglucosan $(\mathrm{m} / \mathrm{z}$, 85 ; fragment - see text), oxalic acid $(\mathrm{m} / \mathrm{z}, 91)$, and cis-pinonic acid $(\mathrm{m} / \mathrm{z}, 167$; fragment - see text).

at $70{ }^{\circ} \mathrm{C}$ (Oja and Suuberg, 1999). Levoglucosan was found to fragment upon protonation in both the high and the low $E / N$-mode. The dominant fragment ion signal was observed at $m / z$ 85. Other major fragment ion signals were observed at $\mathrm{m} / \mathrm{z}, 69$ and $\mathrm{m} / \mathrm{z}$ 97. At even lower $E / N$-values $(\sim 50 \mathrm{Td})$ than those routinely used in this study, we observed a characteristic $\mathrm{m} / \mathrm{z} 145$ ion signal which corresponds to dehydrated protonated levoglucosan. Figure 4d shows that the HT-PTRMS time response for levoglucosan is on the order of 8 to $54 \mathrm{~s}$. Oxalic acid is the simplest dicarboxylic acid and it 
is typically used as a reference compound in aerosol studies. We observed a response time for oxalic acid in the range between 11 and $79 \mathrm{~s}$ (Fig. 4e). Cis-pinonic acid is a particle-bound oxidation product of $\alpha$-pinene with an estimated vapour pressure of $7 \times 10^{-7}$ mbar at room temperature (Bilde and Pandis, 2001). We observed protonated cispinonic acid at $m / z 185$, but the dominant product ion was observed at $\mathrm{m} / \mathrm{z} 167$ (dehydrated protonated cis-pinonic acid). Response times between 1 and 6 min were obtained with the HT-PTR-MS instrument (Fig. 4f). This finding implies that near real-time detection should be possible even for very low vapor pressure compounds.

\section{Conclusions and outlook}

We have developed a HT-PTR-MS instrument in which both the ion source and the ion drift tube can be continuously operated at temperatures up to $250^{\circ} \mathrm{C}$. The instrument was characterized in a high $E / N$-mode and in a low $E / N$-mode at an operating temperature of $200^{\circ} \mathrm{C}$. Instrumental sensitivities and limits of detection of the HT-PTR-MS instrument were of similar order to those observed in standard PTR-MS instruments. Instrumental response times for compounds that readily adsorb or condense onto surfaces ("sticky" or lowvolatility compounds) were significantly reduced and were in the sub-second to a few-minutes time regime. Potential applications of the new HT-PTR-MS include on-line measurements of "sticky" or semi-volatile atmospheric trace gases (e.g. flux measurements of ammonia or amines), direct sampling of hot process gases (e.g. sampling of stack gas, engine exhaust gas, biomass burning gas), and the coupling to a particle collection/thermal desorption apparatus for the analysis of non-volatile organic species (e.g. Thornberry et al., 2009; Holzinger et al., 2010). A further improvement in instrument sensitivity and specificity can be obtained if the high-temperature ion source and drift tube are coupled to an orthogonal time-of-flight (oTOF) mass analyzer (Jordan et al., 2009a). As discussed in paragraph 3.2, the QMA 400 quadrupole mass spectrometer negatively discriminates high $\mathrm{m} / \mathrm{z}$-signals, which is not the case for oTOF mass analyzers. In addition, the use of a high mass resolution oTOFanalyzer will provide the exact mass (sum formula) of the analyte (Graus et al., 2010).

Acknowledgements. This work was funded under the program "Nachwuchsförderung der Universität Innsbruck". We thank Troy Thornberry from the NOAA ESRL Chemical Sciences Division for sharing his experience on the use of resistive glass tubes in PTR-MS instruments. We thank Armin Hansel and Tilmann D. Märk for their continued support.

Edited by: A. Zahn

\section{References}

Bilde, M. and Pandis, S.: Evaporation rates and vapor pressures of individual aerosol species formed in the atmospheric oxidation of alpha- and beta-pinene, Environ. Sci. Technol., 35, 3344-3349, 2001.

de Gouw, J. and Warneke, C.: Measurements of volatile organic compounds in the earths atmosphere using proton-transferreaction mass spectrometry, Mass Spectrom. Rev., 26, 223-257, doi:10.1002/mas.20119, 2007.

Graus, M., Müller, M., and Hansel, A.: High Resolution PTR-TOF: Quantification and Formula Confirmation of VOC in Real Time, J. Am. Soc. Mass Spectr., in press, doi:10.1016/j.jasms.2010.02. 006, 2010.

Hansel, A., Jordan, A., Holzinger, R., Prazeller, P., Vogel, W., and Lindinger, W.: Proton-Transfer Reaction Mass-Spectrometry Online Trace Gas-Analysis at the ppb Level, Int. J. Mass Spectrom., 149, 609-619, 1995.

Hohaus, T., Trimborn, D., Kiendler-Scharr, A., Gensch, I., Laumer, W., Kammer, B., Andres, S., Boudries, H., Smith, K. A., Worsnop, D. R., and Jayne, J. T.: A new aerosol collector for on-line analysis of particulate organic matter: the Aerosol Collection Module (ACM), Atmos. Meas. Tech. Discuss., 3, 13611398, 2010,

http://www.atmos-meas-tech-discuss.net/3/1361/2010/.

Holzinger, R., Williams, J., Herrmann, F., Lelieveld, J., Donahue, N. M., and Röckmann, T.: Aerosol analysis using a Thermal-Desorption Proton-Transfer-Reaction Mass Spectrometer (TD-PTR-MS): a new approach to study processing of organic aerosols, Atmos. Chem. Phys., 10, 2257-2267, 2010, http://www.atmos-chem-phys.net/10/2257/2010/.

Hunt, D. and Ryan, J.: Argon-Water Mixtures as Reagents for Chemical Ionization Mass-Spectrometry, Anal. Chem., 44, 1306-1309, 1972.

Jordan, A., Haidacher, S., Hanel, G., Hartungen, E., Märk, L., Seehauser, H., Schottkowsky, R., Sulzer, P., and Märk, T. D.: A high resolution and high sensitivity proton-transfer-reaction time-offlight mass spectrometer (PTR-TOF-MS), Int. J. Mass Spectrom., 286, 122-128, doi:10.1016/j.ijms.2009.07.005, 2009a.

Jordan, A., Haidacher, S., Hanel, G., Hartungen, E., Herbig, J., Märk, L., Schottkowsky, R., Seehauser, H., Sulzer, P., and Märk, T. D.: An online ultra-high sensitivity Proton-transfer-reaction mass-spectrometer combined with switchable reagent ion capability (PTR+SRI-MS), Int. J. Mass Spectrom., 286, 32-38, doi: 10.1016/j.ijms.2009.06.006, 2009b.

Kim, S., Karl, T., Helmig, D., Daly, R., Rasmussen, R., and Guenther, A.: Measurement of atmospheric sesquiterpenes by proton transfer reaction-mass spectrometry (PTR-MS), Atmos. Meas. Tech., 2, 99-112, 2009,

http://www.atmos-meas-tech.net/2/99/2009/.

McFarland, M., Albritton, D. L., Fehsenfeld, F. C., Ferguson, E. E., and Schmeltekopf, A. L.: Flow-drift technique for ion mobility and ion-molecule reaction rate constant measurements. I. Apparatus and mobility measurements, J. Chem. Phys., 59, 6610 6619, doi:10.1063/1.1680041, 1973.

Mielke, L. H., Erickson, D. E., McLuckey, S. A., Müller, M., Wisthaler, A., Hansel, A., and Shepson, P. B.: Development of a Proton-Transfer Reaction-Linear Ion Trap Mass Spectrometer for Quantitative Determination of Volatile Organic Compounds, Anal. Chem., 80, 8171-8177, doi:10.1021/ac801328d, 2008. 
Norman, M., Hansel, A., and Wisthaler, A.: $\mathrm{O}_{2}^{+}$as reagent ion in the PTR-MS instrument: Detection of gas-phase ammonia, Int. J. Mass Spectrom., 265, 382-387, doi:10.1016/j.ijms.2007.06.010, 2007.

Oja, V. and Suuberg, E.: Vapor pressures and enthalpies of sublimation of D-glucose, D-xylose, cellobiose, and levoglucosan, J. Chem. Eng. Data, 44, 26-29, 1999.

Prazeller, P., Palmer, P., Boscaini, E., Jobson, T., and Alexander, M.: Proton transfer reaction ion trap mass spectrometer, Rapid Commun. Mass Sp., 17, 1593-1599, doi:10.1002/rcm.1088, 2003.

Steinbacher, M., Dommen, J., Ammann, C., Spirig, C., Neftel, A., and Prevot, A.: Performance characteristics of a proton-transferreaction mass spectrometer (PTR-MS) derived from laboratory and field measurements, Int. J. Mass Spectrom., 239, 117-128, doi:10.1016/j.ijms.2004.07.015, 2004.

Thornberry, T., Murphy, D. M., Thomson, D. S., de Gouw, J., Warneke, C., Bates, T. S., Quinn, P. K., and Coffman, D.: Measurement of Aerosol Organic Compounds Using a Novel Collection/Thermal-Desorption PTR-ITMS Instrument, Aerosol Sci. Technol., 43, 486-501, doi:10.1080/02786820902763132, 2009.
Warneke, C., de Gouw, J., Lovejoy, E., Murphy, P., Kuster, W., and Fall, R.: Development of proton-transfer ion trap-mass spectrometry: On-line detection and identification of volatile organic compounds in air, J. Am. Soc. Mass Spectr., 16, 1316-1324, doi: 10.1016/j.jasms.2005.03.025, 2005.

Wisthaler, A., Hansel, A., Jordan, A., and Mark, T. D.: Recent developments in proton-transfer-reaction mass spectrometry, in: Photonic, Electronic and Atomic Collisions, edited by: Fainstein, PD and Lima, MAP and Miraglia, JE and Montenegro, EC and Rivarola, RD, 24th International Conference on Photonic, Electronic and Atomic Collisions, Rosario, Argentina, 20-26 July 2005, 462-469, 2006. 